\title{
Aerosol delivery to ventilated newborn infants: historical challenges and new directions
}

\author{
Jan Mazela $\cdot$ Richard A. Polin
}

Received: 14 June 2010 / Accepted: 6 September 2010 /Published online: 28 September 2010

(C) The Author(s) 2010. This article is published with open access at Springerlink.com

\begin{abstract}
There are several aerosolized drugs which have been used in the treatment of neonatal respiratory illnesses, such as bronchodilators, diuretics, and surfactants. Preclinical in vitro and in vivo studies identified a number of variables that affect aerosol efficiency, including particle size, aerosol flows, nebulizer choice, and placement. Nevertheless, an optimized aerosol drug delivery system for mechanically ventilated infants still does not exist. Increasing interest in this form of drug delivery requires more controlled and focused research of drug/device combinations appropriate for the neonatal population. In the present article, we review the research that has been conducted thus far and discuss the next steps in developing the optimal aerosol delivery system for use in mechanically ventilated neonates.
\end{abstract}

Keywords Aerosol $\cdot$ Infant $\cdot$ Mechanical ventilation $\cdot$ Drug delivery

\section{Introduction}

Aerosols have been proven to be an effective form of drug delivery. Nevertheless, the development of devices as well as medical agents for aerosolization to treat intubated and mechanically ventilated infants still presents a significant

\section{J. Mazela $(\bowtie)$}

Department of Neonatology,

Poznan University of Medical Sciences,

Poznan, Poland

e-mail: janco@pol-med.com.pl

R. A. Polin

Department of Pediatrics, College of Physicians and Surgeons, Columbia University,

New York, NY, USA challenge. Low tidal volumes (VT) and functional residual capacity, high respiratory rates (RR), a shortened particle residence time, and smaller airway diameters account for the diminished delivery of inhaled aerosols to the lower airways in these infants $[15,31,33]$. There are a limited number of clinical deposition studies in the neonatal population because of the inability to use radiolabeled aerosols [24]. However, despite the paucity of clinical data, aerosols have been used to treat critically ill newborn infants without a clear understanding of the optimal aerosol delivery system, the drug deposition pattern in the lung, and the dose/response relationship for aerosolized medications.

Aerosolized medications are administered to infants with ventilator support as part of routine therapy [6]. Historically, regulatory approvals for the use of nebulizer and delivery systems in the neonatal intensive care unit (NICU) have been based on adult studies or in vitro simulations. In September 2007, the United States Congress passed Title III of the FDA Amendments Act, The Pediatric Medical Device Safety and Improvement Act, requiring that new applications or protocols submitted to the FDA for the use and approval of a medical device must include a description of any pediatric subpopulation that suffers from the condition that the device will treat, diagnose, or cure [68]. This Act prompted the development of new aerosol generators for infants requiring ventilator support [29] as the nebulizers and aerosol delivery systems in use prior to the implementation of this Act were not designed solely for this population.

\section{Clinical studies with aerosolized agents in the NICU}

Aerosolized drugs have been used routinely in the NICU for several decades; however, the results of clinical studies have been generally disappointing. Aerosolized agents were 
first used in critically ill infants more than 40 years ago by Robilliard et al. [59] who administered aerosolized dipalmitoyl-phosphatidylcholine directly into the incubators of premature infants with established respiratory distress syndrome (RDS). In this non-controlled study, they found that respiratory effort decreased in 8 of 11 infants. In contrast, investigators at the University of California, San Francisco, and the University of Singapore were unable to demonstrate a physiological benefit with aerosolized phosphatidylcholine [13]. Other studies in which dipalmitoyl lecithin aerosol was administered to infants with RDS were also "negative" and discouraged the use of aerosolized surfactant therapy for many years [39, 64]. However, in the $1990 \mathrm{~s}$, clinicians once again became interested in aerosolized surfactant therapy as noninvasive mechanical ventilation became more prevalent in the neonatal population. The first study in neonates, using nasal continuous positive airway pressure (nCPAP) in combination with aerosolized surfactant for treatment of RDS, was conducted in 1997. This was a pilot feasibility study in which preterm newborns with moderate RDS requiring pharyngeal CPAP received nebulized SF-RI1 (Alveofact ${ }^{\circledR}$, Boehringer Ingelheim, Ingelheim, Germany) [42]. The procedure was shown to be safe and the study demonstrated that ventilation and oxygenation improved once nebulization of surfactant was initiated. The following year, Arroe et al. [5] tested the efficacy and safety of nebulized colfosceril palmitate (Exosurf ${ }^{\circledR}$, GlaxoSmithKline, Brentford, UK) delivered via nCPAP in preterm newborns. The study reported no adverse effects, but did not demonstrate any improvement in clinical efficacy variables as a result of the treatment. Berggren et al. [8] treated 34 newborns (28-33 weeks post-conceptional age and 1,0152,370 g) with RDS using nCPAP and aerosolized poractant alfa (Curosurf ${ }^{\mathbb{B}}$, Chiesi Pharmaceutici SpA, Parma, Italy). The investigators were also unable to demonstrate the superiority of aerosolized surfactant delivery over nCPAP alone. Finer et al. [26], in a recent clinical study with aerosolized lucinactant (Aerosurf ${ }^{\text {(B) }}$, Discovery Laboratories Inc., Warrington, PA, USA), tested the feasibility and safety of delivering a peptide-containing synthetic surfactant to newborns with early signs of RDS within $1 \mathrm{~h}$ of birth. This study used a clinically approved vibrating mesh nebulizer, the Aeroneb ${ }^{\circledR}$ Pro (Aerogen, Dangan, Galway, Ireland), with a specially designed CPAP adaptor which allows for aerosol administration just below the "Y" connector. The procedure was shown to be safe with a low occurrence of "peridosing events" but lack of efficacy as there was not control group included.

A wide variety of other aerosolized medications have been studied in critically ill infants, demonstrating little to no benefit. Shah et al. [63] published a review in the Cochrane Library on the early administration of inhaled corticosteroids for preventing chronic lung disease (CLD) in ventilated very low-birth-weight infants. The metaanalysis of seven trials found no evidence that the early use of inhaled steroids prevents the development of CLD. All of the studies included in this meta-analysis utilized metered-dose inhalers (MDI), except one study by Jonsson et al. [41] which used a dosimetric jet nebulizer for corticosteroid aerosol generation.

There have been several small clinical studies conducted focusing on the use of aerosolized diuretics for the treatment of infants with developing or established CLD. A recently updated Cochrane Review concluded that in preterm infants older than 3 weeks of life with CLD, the administration of a single dose of aerosolized furosemide improved pulmonary mechanics. However, in view of the lack of data from randomized trials concerning effects on important clinical outcomes, routine or sustained use of aerosolized loop diuretics in infants with (or developing) CLD was not recommended [11]. Of the eight studies comprising this review, only four indicated the type of aerosol generator used: jet and ultrasonic.

The Cochrane Library also reviewed the use of aerosolized bronchodilators for the prevention and treatment of CLD. Only one study, in which CLD was a key clinical outcome, met the criteria for inclusion in the analysis. This double-blinded, multicenter randomized trial compared inhaled beclomethasone in combination with salbutamol vs. beclomethasone alone. There were no statistically significant differences in mortality, CLD, need for parenteral dexamethasone, respiratory infections, or positive blood cultures between the combination with salbutamol and beclomethasone alone. Furthermore, there were no statistically significant differences in the duration of ventilatory support, duration of oxygen supply, or age of weaning from respiratory support (defined as assisted ventilation or oxygen supplementation) between the two treatment groups [53].

Inhaled prostacyclin $\left(\mathrm{PGI}_{2}\right)$ has been administered to newborns with persistent pulmonary hypertension (PPHN) $[10,43,66]$ and to infants with PPHN following surgical repair of congenital heart disease [12]. These studies showed improvement in oxygenation due to the decrease of intrapulmonary shunt after treatment with aerosolized $\mathrm{PGI}_{2}$. Nevertheless, these observations were never confirmed by subsequent large multicenter randomized trials.

The clinical trials summarized above provide no clear evidence of efficacy with aerosolized agents in the neonatal population. Furthermore, different aerosol generators were used in these studies. It is important to remember that residual volumes vary among devices. Dubus et al. [23] reported residual volumes of 0.1 and $1.1 \mathrm{~mL}$ for vibrating mesh and jet nebulizers, respectively. Such factors as gas flows and different output rates could influence the emitted dose. Thus, variations in device characteristics among studies make it 
difficult to provide an objective comparison of clinical outcomes.

\section{Mechanical ventilation and aerosol delivery}

Placement and type of the aerosol generator

There are only a few options for aerosol entrainment within the ventilator circuit: (1) placement of the nebulizer within the inspiratory arm of the circuit or (2) introducing the aerosol between the "Y" connector and patient interface. Connecting the nebulizer to the inspiratory arm via a " $T$ " shape connector is recommended for MDIs (Fig. 1a-d), vibrating mesh nebulizers, and jet nebulizers (Fig. 2). Entraining the aerosol between the "Y" connector and patient interface is used mainly for MDIs with a holding chamber (Fig. 3), although some recent studies have also suggested the utility of the placement of vibrating mesh nebulizers in this location whenever a nebulizer with a low residual volume is used [19, 22, 29] (Fig. 4). The general overview of clinically used aerosol generators as well as the most critical variables influencing the effectiveness of aerosolized formulations used for mechanically ventilated infants are included in Table 1.

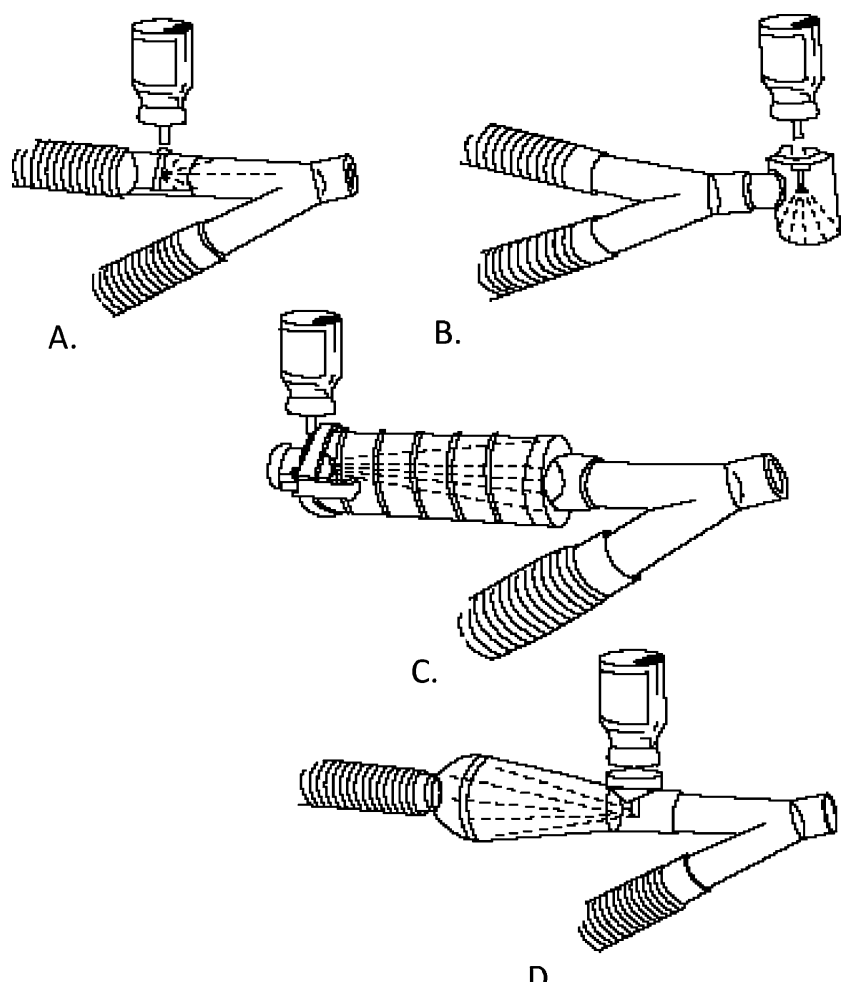

Fig. 1 Different options for MDI placement within ventilator circuit. (From Dhand R, Tobin MJ: Bronchodilator delivery with metereddose inhalers in mechanically ventilated patients. Eur Respir J 9:585, 1996. With permission)

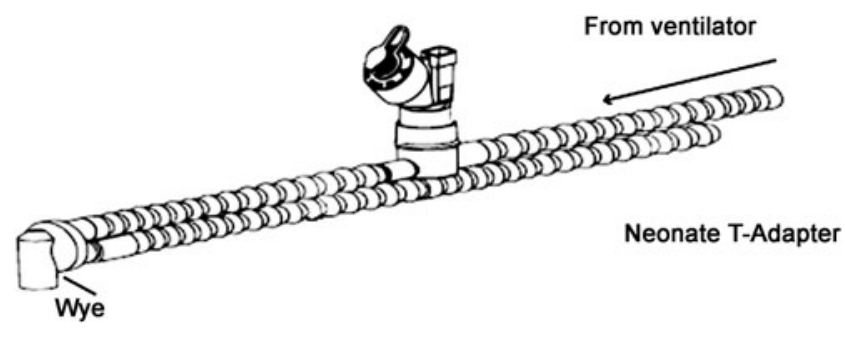

Fig. 2 In-line placement of the aerosol generator within the inspiratory limb of the neonatal ventilator circuit. (From Aeroneb ${ }^{\circledR}$ Solo System instruction manual (Aerogen))

Fok et al. [31] compared different aerosol generators in delivering salbutamol labeled with technetium-99m $\left({ }^{99 m} \mathrm{Tc}\right)$ to infants with bronchopulmonary dysplasia (BPD). The particle size (mass median aerodynamic diameter (MMAD) and geometric standard deviation (GSD)) measured at the end of the endotracheal (ET) tube generated by MDI placed between "Y" and the ET tube via a holding chamber were $1.88 \pm 0.01$ and $1.45 \pm 0.03 \mu \mathrm{m}$, respectively. When a jet nebulizer (Side Stream; MedicAid, UK) with a gas flow rate of $6 \mathrm{~L} / \mathrm{min}$ was placed within the inspiratory arm of the ventilator circuit, the aerosol MMAD was $0.83 \pm 0.01 \mu \mathrm{m}$ and the GSD was $1.69 \pm 0.02 \mu \mathrm{m}$. The aerosols delivered to the infants by jet nebulization were significantly finer than those delivered by MDI $(p=0.005)$. Despite the larger particle size, the MDI was associated with a significantly higher pulmonary deposition relative to the jet nebulizer when results were expressed as a percentage of initial nebulizer reservoir activity (nominal dose; $0.19 \%$ vs. $0.08 \%$, resp., $p=0.009$ ). These data suggest that for intubated infants, smaller particle size at the aerosol generator does not ensure a superior pulmonary deposition and that the type and location of the nebulizer may also influence the lung deposited dose. Dubus et al. showed that the vibrating mesh nebulizer (Aeroneb Pro) was superior in pulmonary deposited dose when compared to the jet nebulizer (MistyNeb; Airlife Inc., Montclair, CA, USA) when both nebulizers were placed in the same location in the inspiratory arm of the ventilator circuit with a MMAD of $1.4 \mu \mathrm{m}$ measured at the end of the ET tube. This finding indicates that device characteristics may drive clinical outcomes.

Based on Fok's and Dubus's findings, it appears that aerosol entrainment into the ventilator circuit is as important as particle size in lung deposition. In these

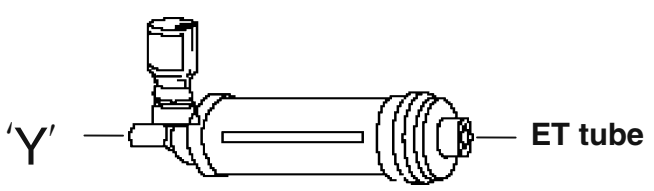

Fig. 3 MDI placement between ' $Y$ ' connector and patient interface with holding chamber. (Modified from Dhand R, Tobin MJ: Bronchodilator delivery with metered-dose inhalers in mechanically ventilated patients. Eur Respir J 9:585, 1996) 


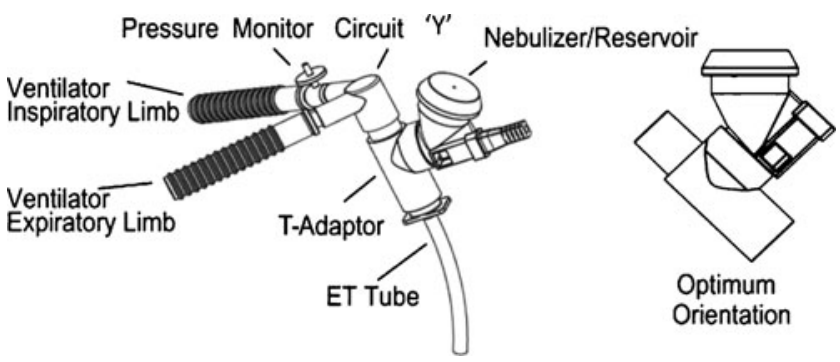

Fig. 4 Placement of the mesh vibrating aerosol generator between ' $Y$ ' connector and ET tube. (Pulmonary drug delivery system (PDDS) connects to low-volume adapter that is connected to patient interface. This system optimizes the aerosol delivery to LRT in mechanically ventilated patients (Aerogen))

studies, the jet and vibrating mesh nebulizers were placed within the inspiratory limb of the ventilator circuit, whereas the MDI was connected to the holding chamber placed between the "Y" connector and the ET tube [31]. Entraining the aerosol into the inspiratory arm of the circuit resulted in considerable dilution of the aerosol because inspiratory flows were much lower than the ventilator circuit flow rate especially when a jet nebulizer was used with an additional $6 \mathrm{~L} / \mathrm{min}$ gas driving flow. Furthermore, the use of higher airflows in the ventilator circuit can lead to the impaction of aerosol within the ventilator circuit before reaching the patient. It is also possible that very small particles (below $1 \mu \mathrm{m}$ ) generated by the jet nebulizer (with relatively low inspiratory flows) were exhaled, leading to reduced lung deposition [56].
Valved holding chambers (VHC) are used in order to optimize aerosol particle size generated by MDIs. The VHC allows time and distance for particle shrinkage and also acts as a large particle filter [20]. Removing the chamber may increase the impaction of aerosol within the ET tube (up to $90 \%$ of the aerosolized dose) [58]. However, it is important to remember that the placement of VHC, or even a "T" connector between the "Y" connector and patient interface, can increase ventilation dead space. Holding chambers can also be placed within the inspiratory arm of the ventilator circuit. Using a lung model, O’Doherty et al. [55] demonstrated that such placement of the chamber increased aerosol delivery due to continuous filling of the chamber with aerosol during the exhalation phase of the breathing cycle, but had no effect on particle size. It has also been shown that electrostatic charge can have a major influence on the delivery of salbutamol generated by MDI [72]. Nevertheless, coating the plastic chamber with an ionic detergent solved the problem of electrostatic charge by the buildup of a conducting layer on the chamber surface and improved aerosol delivery from plastic VHC [72].

Placement of the nebulizer closer to the patient (between the ET tube and the "Y" connector) avoids potential dilution of the aerosol by the higher ventilator airflow rates. Using a neonatal lung model, Turpeinen and Nikander [69] demonstrated that placement of the nebulizer at the ET tube level improved drug delivery compared to in-line nebulizer placement within the inspiratory arm of the ventilator circuit. Nevertheless, clinical studies with

Table 1 Characteristics of different aerosol generators used for ventilated infants

\begin{tabular}{|c|c|c|c|c|}
\hline & Jet & Vibrating mesh & Ultrasonic & MDI \\
\hline $\begin{array}{l}\text { Principle } \\
\text { of aerosol } \\
\text { generation }\end{array}$ & $\begin{array}{l}\text { Pressurized gas forms a } \\
\text { jet passing over a capillary } \\
\text { tube that draws liquid } \\
\text { formulation into the } \\
\text { jet stream }\end{array}$ & $\begin{array}{l}\text { Aerosol is produced by } \\
\text { micropumping action } \\
\text { of the vibrating mesh } \\
\text { containing } 1,000 \\
\text { funnel-shaped holes }\end{array}$ & $\begin{array}{l}\text { Piezoelectric crystal converts } \\
\text { an electrical signal into } \\
\text { high-frequency vibrations } \\
\text { and creates a standing wave } \\
\text { in the medication and } \\
\text { produces aerosol }\end{array}$ & $\begin{array}{l}\text { Active drug is suspended in } \\
\text { propellant which provides } \\
\text { the force to generate the } \\
\text { aerosol cloud when } \\
\text { released from the canister }\end{array}$ \\
\hline Gas flow & Active & Passive & Passive & Passive \\
\hline $\begin{array}{l}\text { Location } \\
\text { within circuit }\end{array}$ & Inspiratory arm & $\begin{array}{l}\text { Inspiratory arm or between } \\
\text { "Y" and ET tube }\end{array}$ & Inspiratory arm & $\begin{array}{l}\text { Inspiratory arm or between } \\
\text { "Y" and ET tube }\end{array}$ \\
\hline $\begin{array}{l}\text { Residual } \\
\text { volume }\end{array}$ & Large & Small & Small & VHC size \\
\hline $\begin{array}{l}\text { Aerosol } \\
\text { particle size }\end{array}$ & $\begin{array}{l}\text { Depends on gas flow } \\
\text { and formulation }\end{array}$ & $\begin{array}{l}\text { Depends on mesh } \\
\text { and formulation }\end{array}$ & Depends on formulation & $\begin{array}{l}\text { Depends on VHC size } \\
\text { and type }\end{array}$ \\
\hline $\begin{array}{l}\text { Aerosol } \\
\text { temperature }\end{array}$ & Low & Ambient & Ambient & Ambient \\
\hline $\begin{array}{l}\text { Efficacy } \\
\text { expressed } \\
\text { as inhaled } \\
\text { dose } \% \text { of } \\
\text { nominal dose }\end{array}$ & Lower & Higher & Mid & Mid \\
\hline
\end{tabular}

$E T$ endotracheal, " $Y$ " wye ventilator circuit connector, $V H C$ valve holding chamber 
sodium cromoglycate did not show improvement in aerosol lung deposition ( $<1 \%$ of the nominal dose) with placement of the nebulizer closer to the patient [71]. Other studies have demonstrated enhanced lung deposition with placement of the nebulizer $<30 \mathrm{~cm}$ from the "Y" connector within the inspiratory arm. This suggests that ventilator tubing can assume the function of an aerosol reservoir [38, 55]. However, such a distal placement of the nebulizer from the patient does not allow for synchronizing aerosol generation with the patient's breathing pattern. Furthermore, the constant high ventilator gas flow within the inspiratory arm of the circuit can lead to aerosol dilution and impaction before reaching patients' airways, as mentioned previously.

A recently published in vitro study by Ari et al. using a pediatric lung model reported two important findings. First, they noted that the vibrating mesh nebulizer was superior to a jet nebulizer in aerosol delivery when efficiency was expressed as a percentage of the nominal dose inhaled. Secondly, they noted that the inhaled dose was higher when the mesh vibrating nebulizer was placed in proximity to the ventilator, just before humidifier with pediatric ventilator settings. Nevertheless, it should be noted that neonatal VT values are significantly lower and ventilator bias flows are usually higher due to potential leaks around uncuffed ET tubes, leading to potential dilutions of the aerosol within ventilator circuitry [5].

In summary, if a MDI is used, the VHC can be placed either in the inspiratory arm of the circuit or between "Y" and the ET tube. If a jet or vibrating mesh nebulizer is used, they should be placed within the inspiratory arm; nevertheless, the exact location should be determined by well-designed clinical studies. The ventilator setting should be adjusted if additional nebulizer driving gas flow is used. The vibrating mesh nebulizer results in superior lung deposition of the drug, most likely due to the smaller residual volume and low operational gas flows.

\section{Mode of ventilation}

Ventilator settings may also play a role in aerosol lung deposition. Fink et al. [27] studied the effect of different modes of ventilation on aerosol delivery from an MDI using an in vitro model. This allowed for a comparison of controlled mechanical ventilation, assist control, pressure support, and continuous positive pressure modes. The study demonstrated significantly higher aerosol deposition within the lower respiratory tract (LRT) with spontaneous breaths under CPAP. Moreover, LRT deposition was linearly related to the duty cycle (inspiratory time/total breath duration). Andersen and Klausen [3] showed that in a spontaneously breathing adult, the use of positive end expiratory pressure (PEEP) with aerosolized albuterol improved lung function better than delivering aerosol without PEEP. Unfortunately, a similar analysis on ventilated infants was not performed. Hess et al. [36] studied the relationship between albuterol delivery and pressure control vs. volume control ventilation in vitro. Their study showed that albuterol delivery using a nebulizer (continuous aerosol generation) was affected by the inspiratory time and inspiratory flow pattern. However, when a pressurized MDI (intermittent aerosol generation) was used, aerosol delivery was not influenced by the inspiratory flow pattern, inspiratory time, or lung mechanics. The use of synchronized nasal intermittent positive pressure ventilation might lead to an improvement in aerosol delivery to the lower respiratory tract, although this has not been proven in an in vivo study.

\section{Humidity}

Standard of care ventilator support requires the delivery of humidified and heated air to patients in order to avoid drying the airway mucosa $[60,62]$. Several in vitro studies have investigated the relationship between humidification and aerosol lung deposition. Miller et al. [49], using different jet nebulizers (AeroTech II $^{\circledR}$, CIS-US, Bedford, MA, USA, and Portex ${ }^{\circledR}$, SIMS Portex, Inc., Fort Myers, FL, USA) and three different ventilators designed for adults (with a driving flow of $8 \mathrm{~L} / \mathrm{min}$ ), demonstrated that aerosol delivery increased nearly twofold $(p<0.0001)$ by turning off and bypassing the humidifier. In addition, humidity increased the particle size at the tip of the ET tube from $1.5 \pm 0.1$ to $2.3 \pm 0.2 \mu \mathrm{m}(p=0.0006)$ by hygroscopic growth, suggesting greater particle impaction in the ventilator tubing. Likewise, other studies showed an approximate $40 \%$ decrease in aerosol lung deposition when humidified and heated air was used [27, 32, 56]. Although studies were conducted under ventilated adult conditions, conclusions related to humidity are applicable to mechanically ventilated infants.

\section{Aerosol conditioning for neonatal applications}

\section{Air flow}

Jet nebulizers use airflow to generate the aerosol. Different commercially available jet nebulizers have different airflow parameters in order to reach optimized performance. Ultrasonic or mesh vibrating nebulizers need gas flow in order to entrain and carry aerosol toward the patient, although airflow is not required to generate the aerosol [35]. Coleman et al. [16] tested different nebulizer airflows in combination with mechanical ventilation in a lung model with settings selected to simulate a 4-kg infant with 
moderate to severe pulmonary disease. A jet nebulizer (Airlife $^{\mathrm{TM}}$ Misty-Neb ${ }^{\mathrm{TM}}$ Baxter, Valencia, CA, USA) was used in this study and was positioned in the inspiratory arm of the ventilator circuit. The study demonstrated that as the nebulizer airflow increased, delivery to the lung model significantly decreased in a linear fashion; the mean percent delivery at $5 \mathrm{~L} / \mathrm{min}$ was $4.8 \pm 1.3 \%$, whereas increasing the flow to $6.5 \mathrm{~L} / \mathrm{min}$ significantly decreased the mean percent delivery to $3.7 \pm 1.1 \%$. Further increasing the flow to $8.0 \mathrm{~L} / \mathrm{min}$ resulted in a significant decrease in the mean percent delivery to $2.7 \pm 1.1 \%(p<0.015$ vs. $5 \mathrm{~L} / \mathrm{min})$. This study also demonstrated higher aerosol deposition within the inspiratory arm of the ventilator circuit with higher airflows, which was most likely related to impaction. Similar relationship between aerosol inhaled dose and ventilator bias flow was also reported by Ari et al. [4]. Using a premature infant nosethroat model, Minocchieri et al. [51] showed that higher aerosol flows lead to reduced lung deposition. There was a statistically significant decrease in aerosol delivery from $61.8 \pm 5.3 \%$ to $26.0 \pm 1.5 \%$ and $9.0 \pm 0.8 \%$ of nominal dose for 1,5 , and $10 \mathrm{~L} / \mathrm{min}$ of inspiratory flow, respectively. An important limitation of this study was the utilization of a continuous airflow through the upper airway model rather than a variable flow model that would have mimicked the patients' breathing pattern.

These in vitro studies have demonstrated that increased airflow presumably leads to increased aerosol impaction in the upper airways, resulting in decreased drug delivery and deposition in the lungs. The use of in vitro models has been shown to provide an acceptable assessment of delivery in vivo $[33,71]$.

\section{Breath-actuated aerosol generation}

Synchronization of nebulizer actuation with the patient's breathing pattern allows for significant reduction of drug losses during exhalation and has been shown to improve the inhaled dose in adult patients [49]. Thus, whenever drug deposition is presented as values of inhaled mass as a function of nominal dose, the values will be improved. A study conducted by Turpeinen and Nikander [69] using a test lung mimicking a ventilated premature infant showed that breath-synchronized nebulization and placement of the nebulizer directly below the "Y" connector resulted in a significantly higher deposition on the inspiratory filters when the deposited dose was expressed as part of the nominal dose. In contrast, non-synchronized nebulization and aerosol generator placement within the inspiratory arm of the ventilator circuit resulted in a lower deposited dose. Nevertheless, it is not clear if these observations are an effect of the nebulizer location, breath synchronization, or type of the nebulized formulation [69]. There is only one animal study evaluating the effectiveness of breath- synchronized nebulization on LRT drug delivery to ventilated infants. Dubus et al. [23] compared lung deposition of radiolabeled aerosol generated by three different delivery systems (Misty-Neb with continuous mode and Aeroneb Pro with and without breathing actuation) in macaque monkeys. Surprisingly, the results did not show any significant difference in the deposited dose in the lung between synchronized and continuous nebulization $(14 \%$ vs. $12.6 \%$ of the nominal dose, respectively). Nevertheless, the deposition values achieved in this study are higher than those previously reported by other investigators.

Infants, especially preterm infants, pose a significant technological challenge in this particular area because of high respiratory rates (RR) and short inspiratory times (IT) [15]. Moreover, flow and pressure-based sensors can be damaged by aerosols, and their placement within the aerosol flow and in close proximity to the patient is not advisable. However, there are other technologies that can be used for breath-synchronized nebulization such as Graseby pneumatic capsule (Graseby Dynamics Ltd., Watford, UK) [40] or neurally adjusted ventilator assist technology (Maquet Inc., Bridgewater, NJ, USA) [65]. Neither of these methods requires sensors placed within the ventilator tubes and thus do not cause additional risks for aerosol impaction. Breath-synchronized nebulization could potentially improve drug delivery compared with continuous nebulization by limiting drug loss during exhalation [54]; nonetheless, there is a need for more in vivo data from ventilated infants.

\section{Particle size}

Recent studies of aerosol lung deposition in term and preterm infants have used an indirect method to assess lung deposition using a marker substance, sodium cromoglycate, which can be measured in the urine. Kohler et al. [44] compared aerosol delivery to non-intubated spontaneously breathing infants using three different nebulizers: jet nebulizer (LC Star ${ }^{\circledR}$; Pari, Starnberg, Germany), ultrasonic nebulizer (LS $290^{\circledR}$; Systam, Villeneuve sur Lot, France), and ultrasonic nebulizer (Projet ${ }^{\mathbb{R}}$; Artsana, Grandate, Italy). During the aerosol dosing, sleeping infants breathed through a face mask covering both the mouth and nose. The highest lung deposition was noted for LC Star jet nebulizer compared with the LS290 and Projet nebulizers $(0.089 \pm 0.036$ vs. $0.055 \pm 0.019$ and $0.046 \pm$ $0.025 \mathrm{mg}$, respectively). The LC Star jet nebulizer used the highest flow rate $(7.55 \pm 0.18 \mathrm{~L} / \mathrm{min})$ and had the highest mass percentage of droplets below $2 \mu \mathrm{m}(20.3 \pm 0.7 \%)$. The amount of sodium cromoglycate retained in each nebulizer after testing was significantly higher for Projet nebulizer. The authors concluded that for spontaneously breathing infants, fine aerosol particles $(<2 \mu \mathrm{m})$ are more likely to reach the lower airways. Nevertheless, the higher deposited dose from LC Star might also be a function of the smaller nebulizer's 
residual volume and not only related to particle size. Furthermore, the level of cromoglycate in the urine does not give direct indication of lung deposition.

Although the LC Star had the highest lung deposition among the other nebulizers, only $0.89 \%$ of the nominal dose was deposited in the lungs after inhalation via LC Star [44]. This finding is supported by other studies on infants showing pulmonary deposition of $<1 \%$ of the nominal dose for spontaneously breathing and mechanically ventilated patients $[2,33]$. Significantly greater direct lung deposition was reported in an in vivo study done on intubated and mechanically ventilated macaque monkeys with the use of Aeroneb Pro and ${ }^{99 \mathrm{~m}} \mathrm{Tc}$ diethylenetriamine pentaacetate. In this study, Dubus et al. [23] reported aerosol with MMAD of $1.4 \mu \mathrm{m}$ at the tip of the ET tube for both tested devices but a 25 -fold greater lung deposition of radiolabeled aerosol when generated by Aeroneb Pro synchronized with inspiration vs. Misty Neb in continuous mode ( $14 \%$ vs. $0.5 \%$ of the nominal dose, respectively). These observations from clinical and non-clinical studies indicate that fine particle sizes that bypass artificial airways and upper airways can be effectively delivered into the lungs of ventilated patients and that differences in residual volumes between nebulizers can drive deposition rates if they are expressed as percent of nominal dose.

However, at the same time, small particles in combination with short (ITs) and low inspiratory flows increase the risk of exhalation drug losses. Fok et al. [31] demonstrated inferior lung deposition in infants with BPD treated with smaller aerosol particles (MMAD of $0.83 \pm 0.01 \mu \mathrm{m}$ ) vs. larger aerosol particles (MMAD of $1.88 \pm 0.01 \mu \mathrm{m}$ ). It has been shown that small particles $(<1 \mu \mathrm{m})$ are less dependent on gravitation and can be exhaled without deposition in the lungs. Calculations as well as actual measurements based on adult models have indicated that particles between 2 and $6 \mu \mathrm{m}$ are deposited in central airways and those above $6 \mu \mathrm{m}$ are deposited in the oropharynx [21]. Studies evaluating particle size delivery to the upper airway of the preterm infants are limited. Minocchieri et al. [50], using an upper airway model comparable to a 32-week gestation infant, reported similar results. In this study, the average MMAD of budesonide particles which passed upper airways was $1.6 \mu \mathrm{m}$. However, model-based studies do not account for amounts of exhaled drug and the results are reflecting only theoretical assumptions that should be supported by in vivo experiments.

O'Riordan et al. [56] showed that the majority of the deposition within the tracheostomy tube occurred during the exhalation phase of the breathing cycle, suggesting that a significant fraction of inhaled aerosol was actually exhaled. Intubated adults were mechanically ventilated and treated with saline labeled with ${ }^{99 \mathrm{~m}} \mathrm{Tc}$ bound to human serum albumin. Aerosol was generated with jet nebulizer AeroTech II and entrained into the inspiratory arm of the ventilator circuit with a MMAD of $1.1 \mu \mathrm{m}$ and GSD of $1.8 \mu \mathrm{m}$. The study reported that $53 \%$ of the total inhaled dose was deposited in the lung, with the remainder of the dose exhaled and deposited in the tracheostomy tube or expiratory arm of the circuit [56]. Although this study was conducted in ventilated adults, the results might be of importance for ventilated infants for whom short inspiratory times are likely to increase the risk of exhalation losses. Heyder et al. [37] demonstrated that only $20-30 \%$ of the submicron aerosol passing beyond the mainstem bronchi was ultimately retained in the lungs; the remainder was expired.

In summary, for intubated and non-intubated infants who require breathing support, the most critical variable influencing particle size is patient interface. The particles should be small enough to bypass that interface with minimal impaction losses, but should not be too small in order to avoid significant exhalation losses. It is important to remember that particle size is only one of many variables that can influence pulmonary drug deposition. Others include: output rate, driving flow rate, and device residual volume.

\section{Type of nebulized formulation}

Turpeinen and Nikander [69] have reported significant improvements in the emitted dose at the ET tube when synchronized nebulization was used with the aerosol generator placed close to the ET tube vs. continuous nebulization with the generator placed within the inspiratory arm of the neonatal ventilator circuit. Interestingly, it was also reported that irrespective of nebulizer synchronization and placement, a solution of terbutaline was superior to a suspension of budesonide in terms of emitted dose through an ET tube. The authors concluded that a solution preparation was superior to a suspension in terms of drug delivery via an ET tube.

Surfactants represent a significantly different class of pharmaceutical agents due to chemical characteristics as well as biophysical activity. Some studies suggest that aerosolized surfactants may be associated with improved pulmonary distribution when compared to a standard liquid intratracheal instillation. Wagner et al. [70] demonstrated in an intubated animal model that atomized surfactant with a droplet size of $120 \pm 4 \mu \mathrm{m}$, administered to the trachea via a catheter, achieved better distribution in the lungs than liquid bolus instillation. Wagner's results suggest that large particles of aerosolized surfactant when passed through vocal cords form a film at the air/liquid interface that spread to the alveoli along the surface tension gradient. Marcinkowski et al. [46] showed that compared to saline, the dispersion area of an aerosolized surfactant was significantly improved after deposition onto mucus or epithelial cell culture surfaces. This 
finding further suggests that with aerosolized surfactant, there is no need to aim the terminal airways as the final target for delivery. The ability of surfactants to spread along mucosal surfaces suggests a special role for them as potential carriers for different aerosolized agents, which can lead to improved lung deposition and more uniform drug distribution.

Finer et al. [26] recently showed that highly viscous solutions such as surfactants may influence nebulizer output rates, in turn, leading to suboptimal emitted dose. These findings indicate the need for the additional testing of drugs with various devices.

Upper airways and gastric deposition

Aerosol deposition in the upper airways presents a continuous challenge for pulmonologists. Amirav et al. [2] studied spontaneously breathing, wheezing infants (119 months of age) who received radiolabeled aerosolized salbutamol (Ventolin ${ }^{\circledR}$, GlaxoSmithKline) with an MMAD of $4.2 \mu \mathrm{m}$. The results showed that total lung deposition varied from $2.4 \%$ to $2.6 \%$, while a statistically significant and clinically relevant benefit was observed among treated patients, as reflected in improved oxygen saturation and reduced respiratory rate. The authors also noted that in addition to local oropharyngeal deposition, any aerosol deposited in the upper respiratory tract was subsequently swallowed and detected in the gastrointestinal tract, accounting for $7.6 \%$ to $8.4 \%$. This observation is important for future development of aerosol therapies and demonstrates the need for the accurate determination of gastrointestinal tract losses.

Impaction of aerosol in upper airways can be limited or avoided by generating small aerosol particles or by bypassing this anatomical region, e.g., by using a nasopharyngeal tube
[47]. The nasal cavity with or without ciliated epithelium acts like a filter and can limit the aerosol delivery into the lower airways [7, 61]. In this regard, Jorch et al. [42] bypassed the upper airways with a single nasal pharyngeal (SNP) tube and showed that aerosolized surfactant combined with CPAP significantly decreased the alveolar-arterial oxygen gradient $\left((\mathrm{A}-\mathrm{a}) \mathrm{O}_{2}\right)$, Silverman score, and $\mathrm{PaCO}_{2}$ in comparison to treatment with CPAP alone. Although this was a small pilot study, the utilization of an SNP tube for CPAP delivery has been applied in other neonatal clinical trials $[52,67]$ and holds a potential to be a very useful approach for aerosol delivery.

Table 2 summarizes all variables presented above that can influence inhaled dose while the infant is on mechanical ventilation.

\section{Inhaled dose calculations}

Each aerosolization system has its own characteristics of the emitted dose and aerosol concentration. The delivered dose is the amount of the drug dispensed from the device to the patient (available to the patient) per minute and is called the emitted dose $\left(E_{\mathrm{d}}\right)$. Aerosol concentration $(C)$ is the amount of the drug per gas carrier volume, which depends on peak inspiratory flow (PIF) [21]. Assuming that an aerosol generator has a constant output rate, the amount of the drug available to the patient can be regulated by the length of treatment. The inhaled dose is the amount of the drug inspired by a patient during the breathing cycle; it is not the same as the deposited dose. The variables that will determine the amount of drug inhaled by a patient include: minute ventilation $\left(V_{\mathrm{m}}\right.$, tidal volume and respiratory rate) [15], aerosol concentration [47], and length of treatment. $V_{\mathrm{m}}$ increases with patient size, although the value per body

Table 2 Factors influencing inhaled dose in mechanically ventilated infants

\begin{tabular}{|c|c|c|c|c|c|}
\hline \multicolumn{2}{|c|}{ Mechanical ventilation-dependent } & \multicolumn{2}{|c|}{ Aerosol generator-dependent } & \multicolumn{2}{|c|}{ Formulation-dependent } \\
\hline$\uparrow$ Inhaled dose & $\downarrow$ Inhaled dose & $\uparrow$ Inhaled dose & $\downarrow$ Inhaled dose & $\uparrow$ Inhaled dose & $\downarrow$ Inhaled dose \\
\hline CPAP & IMV & $\mathrm{MMAD}=1-3 \mu \mathrm{m}$ & MMAD $<1$ and $>3 \mu \mathrm{m}$ & Aqueous solutions & Viscous solutions \\
\hline Bigger VT & Smaller VT & Small residual volume & Large residual volume & Solutions & Suspension \\
\hline Lower RR & Higher RR & MDI with VHC & MDI without VHC & Temperature $=36^{\circ} \mathrm{C}$ & Temperature $<36^{\circ} \mathrm{C}$ \\
\hline Longer IT & Shorter IT & Detergent coated VHC & Non-coated VHC & & \\
\hline Larger ET tube & Smaller ET tube & Aerosol flow $=$ PIF & Aerosol flow $>$ or $<$ PIF & & \\
\hline Dry gas & Humid gas & $\begin{array}{l}\text { Synchronized } \\
\text { actuations/release }\end{array}$ & $\begin{array}{l}\text { Non-synchronized } \\
\text { actuations/release }\end{array}$ & & \\
\hline $\begin{array}{l}\text { Low ventilator } \\
\text { bias flow }\end{array}$ & $\begin{array}{l}\text { High ventilator } \\
\text { bias flow }\end{array}$ & & & & \\
\hline
\end{tabular}

$C P A P$ continuous positive airway pressure, $I M V$ intermittent mechanical ventilation, $M M A D$ mass median aerodynamic diameter, $V T$ tidal volume, $R R$ respiratory rate, $M D I$ metered dose inhaler, $V H C$ valve holding chamber, $E T$ endotracheal, $P I F$ peak inspiratory pressure 
weight remains constant for relatively wide neonatal weight ranges [9]. Based on these assumptions, the inhaled dose can be presented as:

$$
\text { Inhaled Dose }=C\left[\mathrm{mg} \mathrm{L} L^{1}\right] \times V_{\mathrm{m}}\left[\mathrm{Lmin}^{-1} \mathrm{~kg}^{-1}\right] \times T[\mathrm{~min}]
$$

where $C$ (aerosol concentration) is based on the emitted dose from the system under known flow conditions and $V_{\mathrm{m}}$ (minute ventilation) is related to the size of the infant. $V_{\mathrm{m}}$ can be calculated based on direct neonatal lung function measurements of spontaneously breathing newborns as presented by Bhutani and Sivieri [9]. $T$ (length of treatment) is the external factor determining the inhaled dose.

This calculation is applicable when two conditions are met: first, a reliable aerosol generator capable of providing a constant output rate must be used. This has been a technical challenge as some off-shelf devices fail to provide constant output rate based on performance testing [16]; second, the aerosol flow rate must equal or exceed the peak inspiratory flow in order to avoid any potential aerosol dilution during the inspiratory phase of the breathing cycle [47].

Based on the calculation for inhaled dose, the deposited dose in the LRT will be equal to the inhaled dose minus the sum of the potential losses at the upper airways [7, 30, 61] and exhaled amount of the drug [37, 56]. Data on aerosol deposition in the neonatal population are very limited (and in premature and ventilated populations do not exist), preventing accurate calculations of delivered doses to the lung.

\section{Other considerations}

\section{Ventilation gases}

Any gas density lower than air or oxygen can reduce airflow turbulence through the narrow airways of the neonate. Fink et al. [28] found that aerosol delivery via a MDI showed a linear increase when the gas density within the ventilator circuit was decreased. The use of an $80 \%$ helium and $20 \%$ oxygen mixture in a dry ventilator circuit resulted in a 50\% increase in the amount of drug delivered to the lower respiratory tract compared with that observed with $100 \%$ oxygen (46.1\% vs. $30.4 \%$ ), respectively [18]. However, it is important to remember that airflow-based jet nebulizers may potentially exhibit decreased output rates when used with helium-oxygen mixtures [22]. Interestingly, noninvasive heliox ventilation has been recently shown to decrease resistive work of breathing and ventilator support requirements as well as improve gas exchange in premature infants [48].
PEEP valve and ambient air contamination

An important technical issue that needs to be considered when aerosol delivery is combined with mechanical ventilation is the potential for contamination of the ventilator PEEP valve with aerosolized agents exhaled by patients. Haas et al. [34] evaluated the efficiency of a supplemental filter system during mechanical ventilation for continuous nebulization of a synthetic surfactant. The results showed that increased filter resistance occurred at $7.3 \pm 1.3 \mathrm{~h}$ of continuous ventilation with a minute ventilation of $20 \mathrm{~L} / \mathrm{min}$. This study also demonstrated the need for an appropriate and continuous pressure monitoring upstream to the expiratory filter in order to detect the increase in baseline pressure associated with expiratory filter occlusion.

\section{Patient interface}

Patient interface can also act as a significant site of aerosol impaction. In an in vitro study, Ahrens et al. [1] investigated the influence of different neonatal ET tube sizes and flows on aerosol deposition in a test lung. The results suggested that aerosol flows were more important than ET tube size on aerosol deposition of conventional aerosols in clinical use $(\mathrm{MMAD}=3.95 \mu \mathrm{m})$. The study also showed that test lung deposition significantly improved when submicronic aerosol $(\mathrm{MMAD}=0.54 \mu \mathrm{m})$ was delivered. Crogan and Bishop [17] showed that the percentage of aerosolized metaproterenol (Alupent ${ }^{\circledR}$, Boehringer Ingelheim) exiting the ET tube almost doubled for a 9.0- vs. 6.0-mm ET tube. Everard et al. [25] showed a drop in drug delivery when using a smaller ET tube (2.5 vs. $3.0 \mathrm{~mm}$ ) during in vitro testing of Babylog Draeger neonatal ventilator circuit, and Dubus et al. [23] reported that regardless of different aerosol particles at the nebulizer outlet, the particle size distribution at the end of the 3.0-mm ET tube was similar with an MMAD of $1.4 \mu \mathrm{m}$ across all tested nebulizers.

As mentioned earlier, these findings show that patient interface can be a critical variable determining the particle size delivered to a mechanically ventilated patient [23]. Unfortunately, there are limited data on the influence of neonatal ET tube size on aerosol characteristics and lung deposition in in vivo studies.

Method of particle size measurement

Although research methodology was not the focus of this review, it is important to point out some nuances related to the methods of particle size measurement as each method has its limitations that could potentially influence the results and conclusions of the studies discussed in this review. There are two generally approved methods to measure particle size. The first, light-scattering techniques including 
laser diffraction analysis and single-particle counters, are used primarily for aqueous solutions and wet aerosols. Recently, the laser diffraction method has been proven to be an acceptable tool for both wet as well as dry aerosols [57]. However, this method lacks resolution for aerosols on the order of $1 \mu \mathrm{m}$. In addition, laser diffraction cannot be applied to suspensions since this method measures droplet size and is unable to determine which droplets contain drug particles [14]. The second method for particle size measurement is based on inertial impaction via cascade impactors used for dry powder aerosols [14]. Cascade impactors operate under high airflow conditions, making this method less applicable to neonatal breathing conditions. The resulting particle size measurements from cascade impactors are temperature-related, with the possibility of re-entrainment of bounced particles from the plates which could overestimate the ratio of smaller particles [14, 45]. We did not analyze the methods used to determine particle size measurement in the presented studies (some of these studies did not address this information). Nevertheless, we acknowledge that the method utilized for particle size measurement could potentially affect the conclusions of some of these studies.

\section{Summary}

Aerosol therapy is routinely used in critically ill neonates despite lack of supporting data from randomized clinical studies. Clearly, there are numerous factors known to contribute to the performance of aerosol delivery systems. Yet, to date, aerosol delivery systems have not been systematically evaluated or approved for use in mechanically ventilated, premature infants. Moreover, prescribing information for currently available aerosolized medications does not contain adequate information on dosage regimens for premature infants. Of particular concern is the fact that therapeutic index, including potential side effects from upper airway or gastrointestinal deposition, has not been adequately characterized.

Based upon what we have learned from the literature, future research in this area should focus on designing appropriate aerosol delivery systems for ventilated neonates that efficiently entrain aerosols without impairment of ventilatory support. For example, (1) inhalation chambers should have an optimal volume or separated inhalation and exhalation pathways to avoid re-breathing if placed between "Y" and the ET tube; (2) aerosol generator location should be specified for certain types of generators, but its placement should minimize potential aerosol dilutions; (3) aerosol flows and particle size should be adjusted to the infant's breathing pattern and minute ventilation to limit any drug losses in the upper airways; (4) aerosol delivery systems including generator should be single-use or resterilized after use to avoid any potential infectious hazards; and (5) aerosol delivery systems should be well characterized including patient interface and should be tested separately for ventilated as well as for spontaneously breathing infants. The availability of such delivery systems for ventilated neonates could optimize the effectiveness of current aerosolized agents (e.g., bronchodilators, antibiotics, and surfactants) with well-defined safety profiles and, in addition, may trigger new research to expand its utility with other therapies and different patient populations.

Acknowledgments We would like to thank Denise Ramjit, BS for her help in editing and submitting the manuscript for publication.

Author disclosure statement Dr. Jan Mazela serves as a clinical consultant to Discovery Laboratories Inc., Dr. Richard Polin serves as a member of the Scientific Advisory Board for Discovery Laboratories, Inc.

Open Access This article is distributed under the terms of the Creative Commons Attribution Noncommercial License which permits any noncommercial use, distribution, and reproduction in any medium, provided the original author(s) and source are credited.

\section{References}

1. Ahrens R, Ries R, Popendorf W, Wiese J (1986) The delivery of therapeutic aerosols through endotracheal tubes. Pediatr Pulmonol 2:19-26

2. Amirav I, Balanov I, Gorenberg M, Groshar D, Luder A (2003) Nebulizer hood compared to mask in wheezy infants: aerosol therapy without tears! Arch Dis Child 88:719-723

3. Andersen J, Klausen N (1982) A new mode of administration of nebulized bronchodilator in severe bronchospasm. Eur J Respir Dis 119(Suppl):97-100

4. Ari A, Atalay O, Harwood R, Sheard M, Aljamhan E, Fink J (2010) Influence of nebulizer type, position, and bias flow on aerosol drug delivery in simulated pediatric and adult lung models during mechanical ventilation. Respir Care 55(7):845-851

5. Arroe M, Pedersen-Bjergaard L, Albertsen P, Bode S, Greisen G, Jonsbo $F$ et al (1998) Inhalation of aerosolized surfactant $\left(\right.$ Exosurf $\left.^{\mathbb{R}}\right)$ to neonates treated with nasal continuous positive airway pressure. Prenat Neonatal Med 3:346-352

6. Ballard J, Lugo RA, Salyer JW (2002) A survey of albuterol administration practices in intubated patients in the neonatal intensive care unit. Respir Care 47(1):31-37

7. Becquemin M, Swift D, Bouchikhi A, Roy M, Teillac A (1991) Particle deposition and resistance in the nose of adults and children. Eur Respir J 4:694-702

8. Berggren E, Liljedahl M, Winbladh B, Andreasson B, Cursted T, Robertson B et al (2000) Pilot study of nebulized surfactant therapy for neonatal respiratory distress syndrome. Acta Paediatr 89(4):460-464

9. Bhutani V, Sivieri E (2003) Pulmonary function and graphics. In: Goldsmith J, Karotkin E (eds) Assisted ventilation of the neonate, 4th edn. Saunders, Philadelphia, pp 293-309

10. Bindl L, Fahnenstich H, Peukert U (1994) Aerosolized prostacyclin for pulmonary hypertension in neonates. Arch Dis Child 71: F214-F216 
11. Brion L, Primhak R, Yong W (2006) Aerosolized diuretics for preterm infants with (or developing) chronic lung disease. Cochrane Library (3):Art. No. CD001694

12. Carroll C, Backer C, Mavroudis C, Cook K, Goodman D (2005) Inhaled prostacyclin following surgical repair of congenital heart disease - a pilot study. J Card Surg 20:436-439

13. Chu J, Clements J, Cotton E, Klaus M, Sweet A, Thomas M et al (1965) Preliminary report: the pulmonary hypoperfusion syndrome. Pediatrics 35:733-742

14. Clark A, Borgstrom L (2002) In vitro testing of pharmaceutical aerosols and predicting lung deposition from in vitro mesurements. In: Bisgaard H, O'Callaghan C, Smaldone G (eds) Drug delivery to the lung (Vol. 162). Marcel Dekker, New York

15. Cole C (2000) Special problems in aerosol delivery: neonatal and pediatric considerations. Respir Care 45(6):646-651

16. Coleman D, Kelly H, McWilliams B (1996) Determinants of aerosolized albuterol delivery to mechanically ventilated infants. Chest 109(6): 1607-1613

17. Crogan S, Bishop M (1989) Delivery efficiency of metered dose aerosols given via endotracheal tubes. Anesthesiology 70:1008-1010

18. Dhand R (2000) Special problems in aerosol delivery: artificial airways. Respir Care 45(6):636-645

19. Dhand R (2008) Aerosol delivery during mechanical ventilation: from basic techniques to new devices. J Aerosol Med Pulm Drug Del 21(1):45-60

20. Dolovich M (1989) Physical principles underlying aerosol therapy. J Aerosol Med 2:171

21. Dolovich M (2000) Influence of inspiratory flow rate, particle size, and airway caliber on aerosolized drug delivery to the lung. Respir Care 45(6):597-608

22. Duarte AG, Fink JB, Dhand R (2001) Inhalation therapy during mechanical ventilation. Respir Care Clin N Am 7(2):233-260

23. Dubus J, Vecellio L, de Monte M, Fink J, Grimbert D, Montharu J et al (2005) Aerosol deposition in neonatal ventilation. Pediatr Res 58(1):10-14

24. Everard M (2003) Ethical aspects of using radiolabeling in aerosol research. Arch Dis Child 88:659-661

25. Everard M, Stammers J, Hardy J, Milner A (1992) New aerosol delivery system for neonatal ventilator circuits. Arch Dis Child 67:826-830

26. Finer N, Merritt T, Bernstein G, Job L, Mazela J, Segal R (2010) An open label, pilot study of Aerosurf combined with nCPAP to prevent RDS in preterm neonates. J Aerosol Med Pulm Drug Del 23:1-7

27. Fink JB, Dhand R, Duarte AG, Jenne JW, Tobin MJ (1996) Aerosol delivery from a metered-dose inhaler during mechanical ventilation. An in vitro model. Am J Respir Crit Care Med 154:382-387

28. Fink JB, Dhand R, Navin D, Fahey P, Tobin M (1997) Heliox improves aerosol delivery from MDI during mechanical ventilation: an in vitro model. Am J Respir Crit Care Med 155:A770

29. Fink JB, Dunne P, MacLoughlin R, O'Sullivan GO (2005) Can high efficiency aerosol delivery continue after extubation. Crit Care 9(Suppl1):129

30. Finlay W, Martin A (2008) The ARLA aerosol deposition calculator. http://www.mece.ualberta.ca/arla/aerosoldepositioncalculator.html

31. Fok T, Monkman S, Dolovich M, Gray S, Coates G, Paes B et al (1996) Efficiency of aerosol medication delivery from a metered dose inhaler versus jet nebulizer in infants with bronchopulmonary dysplasia. Pediatr Pulmonol 21:301-309

32. Fuller H, Dolovich M, Chambers C, Newhouse M (1992) Aerosol delivery during mechanical ventilation: a predictive in vitro lung model. J Aerosol Med 5:251-259

33. Grigg J, Arnon S, Jones T, Clarke A, Silverman M (1992) Delivery of therapeutic aerosols to intubated babies. Arch Dis Child 67(1 Spec No):25-30
34. Hass C, Weg J, Kettell C, Caldwell E, Zaccardelli D, Brown D (1993) Effects of dense, high-volume, artificial surfactant aerosol on a heated exhalation filter system. Crit Care Med 21:125-130

35. Hess D (2008) Aerosol devices in the treatment of asthma. Respir Care 53(6):699-723

36. Hess D, Dillman C, Kacmarek R (2003) In vitro evaluation of aerosol bronchodilator delivery during mechanical ventilation: pressure-control vs. volume control ventilation. Intensive Care Med 29(7):1145-1150

37. Heyder J, Gebhart J, Stahlhofen W (1980) Inhalation of aerosols: particle deposition and retention. In: Willeke K (ed) Generation of aerosols. Ann Arbor Science, Ann Arbor, pp 65-103

38. Hughes J, Saez J (1987) Effects of nebulizer mode and position in a mechanical ventilator circuit on dose efficiency. Respir Care 32:1131-1135

39. Ivey H, Roth S, Kattwinkel J (1977) Nebulization of sonicated phospholipids (PL) for treatment of respiratory distress syndrome (RDS) in infancy. Pediatr Res 12:573

40. John J, Bjorklund L, Svenningsen N, Jonson B (1994) Airway and body surface sensors for triggering in neonatal ventilation. Acta Paediatr 83(9):903-909

41. Jonsson B, Eriksson M, Soder O, Broberger U, Lagercrantz H (2000) Budesonide delivered by dosimetric jet nebulization to preterm very low birthweight infants at high risk for development of chronic lung disease. Acta Paediatr 89(12):1449-1455

42. Jorch G, Hartl H, Roth B, Kribs A, Gortner L, Schaible T et al (1997) To the editor: surfactant aerosol treatment of respiratory distress syndrome in spontaneously breathing premature infants. Pediatr Pulmonol 24:222-224

43. Kelly L, Porta N, Goodman D, Carroll C, Steinhorn R (2002) Inhaled prostacyclin for term infants with persistent pulmonary hypertension refractory to inhaled nitric oxide. J Pediatr 141:830-832

44. Kohler E, Jilg G, Avenarius S, Jorch G (2008) Lung deposition after inhalation with various nebulizers in preterm infants. Arch Dis Child Fetal Neonatal Ed 93:275-279

45. Kwong J, Ho S, Coates A (2000) Comparison of nebulized particle size distribution with Malvern laser diffraction analyzer versus Andersen cascade impactor and low-flow marple personal cascade impactor. J Aerosol Med 13(4):303-314

46. Marcinkowski A, Garoff S, Tilton R, Pilewski J, Corcoran T (2008) Postdeposition dispersion of aerosol medications using surfactant carriers. J Aerosol Med Pulm Drug Del 21(4):1-9

47. Mazela J, Merritt T, Finer N (2007) Aerosolized surfactants. Curr Opin Pediatr 19:155-162

48. Migliori C, Gancia P, Garzoli E, Spinoni V, Chirico G (2009) The effects of helium/oxygen mixture (Heliox) before and after extubation in long-term mechanically ventilated very low birth weight infants. Pediatrics 123(6):1524-1528

49. Miller D, Amin M, Palmer L, Shah A, Smaldone G (2003) Aerosol delivery and modern mechanical ventilation: in vitro/in vivo evaluation. Am J Respir Crit Care Med 168(10):1205-1209

50. Minocchieri S, Bachmann M, Burren J, Kaeser R, Wildhaber J, Nelle M (2006) How small is small enough? Determination of the optimal aerosol particle size for inhalation therapy in preterm infants in vitro. Paper presented at the Europaediatrics, Barcelona

51. Minocchieri S, Burren J, Bachmann M, Stern G, Wildhaber J, Boub S et al (2008) Development of the premature infant nose throat-model (PrINT-Model) - an upper airway replica of a premature neonate for the study of aerosol delivery. Pediatr Res 64(2):141-146

52. Morley C, Davis P, Lex W, Prion L, Hascoet J, Carlin J (2008) Nasal CPAP or intubation at birth for very preterm infants. N Engl J Med 358:700-708

53. Ng G, daSilva O (2006) Bronchodilators for the prevention and treatment of chronic lung disease in preterm infants. Cochrane Library(1). 
54. Nikander K, Turpeinen M, Wollmer P (2000) Evaluation of pulsed and breath-synchronized nebulization of budesonide as a means of reducing nebulizer wastage of drug. Pediatr Pulmonol 29:120-126

55. O'Doherty M, Thomas S, Page C, Treacher D, Nunan T (1992) Delivery of a nebulized aerosol to a lung model during mechanical ventilation. Effect of ventilator settings and nebulizer type, position, and volume of fill. Am Rev Respir Dis 146(2):383-388

56. O'Riordan T, Palmer L, Smaldone G (1994) Aerosol deposition in mechanically ventilated patients. Optimizing nebulizer delivery. Am J Respir Crit Care Med 149(1):214-219

57. Pilcer G, Vanderbist F, Amighi K (2008) Correlations between cascade impactor analysis and laser diffraction techniques for the determination of the particle size of aerosolised powder formulations. Intern J Pharm 358(2):75-81

58. Rau J, Harwood R, Groff J (1992) Evaluation of a reservoir device for metered-dose bronchodilator delivery to intubated adults: an in vitro study. Chest 102(3):924-930

59. Robillard E, Alarie Y, Dagenais-Perusse P, Baril E, Guilbeault A (1964) Micro-aerosol administration of synthetic dipalmityol lecithin in the respiratory distress syndrome: a preliminary report. Can Med Assoc J 90:55-57

60. Ryan S, Rankin N, Meyer E, Williams R (2002) Energy balance in the intubated human airway is an indicator of optimal gas conditioning. Crit Care Med 30(2):355-361

61. Salmon B, Wilson N, Silverman M (1989) How much aerosol reaches the lungs of wheezy infants and toddlers. Arch Dis Child 65:401-403

62. Schulze A (2002) Respiratory gas conditioning in infants with an artificial airway. Semin Neonatol 7(5):369-377

63. Shah V, Ohlson A, Halliday H, Dunn M (2007) Early administration of inhaled corticosteroids for preventing chronic lung disease in ventilated very low birth weight preterm neonates. Cochrane Library (3):Art. No. CD001969

64. Shannon D, Bunnell J (1976) Dipalmitoyl lecithin aerosol in RDS. Pediatr Res 1:467

65. Sinderby C, Navalesi P, Beck J, Skrobic J, Comtois N, Friberg S et al (1999) Neural control of mechanical ventilation. Nat Med 5:1433-1436

66. Sood B, Delanley-Black V, Aranda J, Shankaran S (2004) Aerosolized $\mathrm{PGE}_{1}$ : a selective pulmonary vasodilator in neonatal hypoxemic respiratory failure results of a phase I/II open label clinical trial. Pediatr Res 56:579-585

67. te Pas A, Walther F (2007) A randomized controlled trial of delivery-room respiratory management in very preterm infants. Pediatrics 120(2):322-329

68. Title III-Pediatric Medical Device Safety and Improvement Act of 2007. One hundred tenth Congress of The United States of America, pp 37-44 (2007)

69. Turpeinen M, Nikander K (2001) Nebulization of a suspension of budesonide and a solution of terbutaline into a neonatal ventilator circuit. Respir Care 46(1):43-48

70. Wagner M, Amthauer H, Sonntag J, Drenk F, Eichstadt H, Obladen M (2000) Endotracheal surfactant atomization: an alternative to bolus instillation? Crit Care Med 28(7):2540-2544

71. Watterberg K, Clark A, Kelly H, Murphy S (1991) Delivery of aerosolized medication to intubated babies. Pediatr Pulmonol 10 (2):136-141

72. Wildhaber J, Devadason S, Eber E, Hayden M, Everard M, Summers Q et al (1996) Effect of electrostatic charge, flow, delay and multiple actuations on the in vitro delivery of salbutamol from different small volume spacers for infants. Thorax 51:985-988 